\title{
Transição na Revista de Psiquiatria do Rio Grande do Sul
}

\author{
Transition phase at Revista de Psiquiatria do Rio Grande do Sul
}

\section{Flávio Kapczinski*}

* Editor, Revista de Psiquiatria do Rio Grande do Sul.

Ao longo dos últimos anos, a Revista de Psiquiatria do Rio Grande do Sul (RPRS) consolidou seu papel como uma referência importante no cenário científico. $\mathrm{O}$ layout foi modernizado, e obteve-se um maior rigor na seleção de artigos. Também foi contratado um sistema de submissão eletrônica (2006), com alteração da sistemática de submissão de artigos.

Após a indexação no SciELO e no PsycINFO, aumentou o compromisso da RPRS com a qualidade. Procurou-se assegurar a periodicidade e a pontualidade, o que, juntamente com a implantação do sistema de submissão, aumentou de forma significativa o aporte de artigos originais. Adotou-se o sistema de publicação on-line, sendo mantido o formato impresso somente para os associados da Associação de Psiquiatria do Rio Grande do Sul (APRS) (2008).

Permanecem múltiplos desafios, como a indexação da RPRS no ISI e na PubMed. A Revista segue sua trajetória de aprimoramento e sua missão institucional. Acima de tudo, a qualidade conquistada pela Revista beneficia a comunidade psiquiátrica e se transfere na qualidade do atendimento aos pacientes.

A RPRS agradece pela contribuição dos editores, dos membros do corpo editorial e dos revisores. E, acima de tudo, agradecemos aos autores, que muito contribuíram para a evolução da Revista nestes anos. 